\title{
Chlordecone potentiates auto-immune hepatitis and promotes brain entry of MHV3 during viral hepatitis in mouse models.
}

\author{
Elise Tabet ${ }^{1}$, Moana Gelu-Simeon ${ }^{2}$, Valentine Genet $^{1}$, Lucie Lamontagne ${ }^{3}$, Claire \\ Piquet-Pellorce ${ }^{1}$ and Michel Samson ${ }^{1}$. \\ ${ }^{1}$ Univ Rennes, Inserm, EHESP, Irset (Institut de recherche en santé, environnement et travail) - \\ UMR_S 1085, F 35000 Rennes, France. \\ ${ }^{2}$ Univ Antilles, CHU Pointe-à-Pitre, Univ Rennes, Inserm, EHESP, Irset (Institut de recherche en \\ santé, environnement et travail) - UMR_S 1085, F-97000 Pointe-à-Pitre, France \\ ${ }_{3}^{3}$ Département des Sciences Biologiques, Université du Québec à Montréal, Montréal, Québec, \\ Canada.
}

Address for correspondence: Michel Samson, Inserm-U1085, Irset, Université de Rennes 1, 2, Avenue du Professeur Léon Bernard, 35043 RENNES Cedex, France. Phone (+33) 22323 5927; Fax (+33) 223234794.

Keywords: Liver, Hepatitis, Chlordecone, Kepone, pesticide, viral hepatitis

List of abbreviations: AST: Aspartate aminotransferase, ALT: Alanine aminotransferase, CD: Chlordecone, ConA : concanavalin A, MHV3 : Murine hepatitis virus type 3 .

Conflict of interest: The authors have no financial or commercial conflict of interest to declare.

Word count of manuscript: 4510 with references

Number of figures: 6 main figures and 1 Supplementary figure

Financial support: This work was supported by INSERM, the Ministère de l'Education Nationale de la Recherche et de la Technologie, the ANR CESA Hepatochlor project, the University of Rennes 1, the Région Bretagne, the "Ligue contre le cancer, comités du grand Ouest". 


\section{Abstract (225 words)}

Chlordecone is an organochlorine used in the 1970's as a pesticide in banana plantations. It has a long half-life in the soil and can potentially contaminate humans and animals through food. Chlordecone targets, and mainly accumulates in, the liver, leading to hepatomegaly and neurological signs in mammals. Chlordecone does not cause liver injuries or any inflammation by itself at low doses, but it can potentiate the hepatotoxic effects of other chemicals and drugs. We studied the impact of chlordecone on the progression of acute hepatitis in mouse models of co-exposure to chlordecone with Concanavalin A or murine hepatitis virus type 3 . We examined the progression of these two types of hepatitis by measuring hepatic transaminase levels in the serum and inflammatory cells in the liver, liver histological studies. Amplified tremors presented in the MHV3- chlordecone mouse model had led us to study the expression of specific genes in the brain. We show that chlordecone amplifies the auto-immune hepatitis induced by Concanavalin A by increasing the number of liver NKT cells, which are involved in liver damage. Chlordecone also accelerated the death of mice infected by murine hepatitis virus and enhanced the entry of the virus into the cervical spinal cord in infected mice, leading to considerable neurological damage. In conclusion, chlordecone potentiates both the Concanavalin A-induced hepatitis and brain damage caused by an hepatotropic/neurotropic virus. 


\section{Introduction}

The liver is a vital organ subjected to various insults, including chemical agents, such as xenobiotics or drugs, viruses, and parasites. These agents can induce acute and/or chronic hepatitis. For example, Hepatitis A (HAV) and E (HEV) viruses cause acute, usually self-limiting, illnesses, whereas hepatitis B (HBV), C $(\mathrm{HCV})$, and D (HDV) viruses induce both acute and chronic disease (Ponde, 2017). Repeated liver insults over a long period can result in hepatocyte death, inflammation, and fibrosis, leading to liver failure or the onset of liver cancer. Chlordecone is an organochlorine that was used primarily for agricultural purposes. It is a persistent environmental pollutant and its manufacture and use has led to significant contamination in the United States and the French West Indies that has adversely affected the environment and humans. Among the xenobiotics that affect the liver, chlordecone was shown to induce hepatomegaly in humans and animals in limited occupational and many experimental toxicological studies (Egle et al., 1978; Guzelian, 1982). This pesticide can also induce neurological damage in humans, manifested by convulsions, irritability, and tremors (Cannon SB and Landrigan PJ, 1978; Taylor et al., 1978). The same effects have also been shown in rodent toxicological studies (Huang et al., 1981).

The liver is the main target of chlordecone, where it accumulates due to its ability to bind to plasma lipoproteins, which are responsible for the transport of cholesterol to the liver (Skalsky et al., 1979; Soine et al., 1982). The role of the liver in detoxifying molecules makes it a primary target of toxicity. Chlordecone combined with certain molecules can potentiate their hepatotoxicity, as shown for chloroform (lijima et al., 1983), acetaminophen (Fouse and Hodgson, 1987), and carbon tetrachloride (CCl4) (Klingensmith et al., 1983; Klingensmith and 
Mehendale, 1982). Our group has reported that chlordecone can potentiate hepatic fibrosis in mice with CCl4-induced chronic liver injury (Tabet et al., 2016) and that chlordecone can be quantified and localized in situ in liver by MALDI imaging (Lagarrigue et al., 2014). Here, we investigated the effect of chlordecone in acute hepatitis, caused by an hepatotropic/neurotropic viral agent, and autoimmune liver diseases. Two mouse models of acute hepatitis were developed, the first one by co-exposure of mice to chlordecone and Concanavalin A (Con A) as an inducer of auto-immune hepatitis (Tiegs et al., 1992) and the second by coexposure to chlordecone and mouse hepatitis virus type 3 (MHV3) virus, which induces viral acute hepatitis and which is also neurotropic (Martin et al., 1994).

\section{Materials and Methods}

\section{Animals and experimental protocols}

Eight-week-old male C57BI/6 mice were purchased from Janvier labs (Le Genestsur-Isle, France) and reared under specific pathogen-free (SPF) conditions in the local animal house, in accordance with French laws and institutional guidelines for the handling and care of experimental animals (accreditation of M. Samson \#3596). The mice were divided in a random manner into several groups according to the need of the studies. Those treated with chlordecone (Santa Cruz Biotechnology) were given daily doses of $5 \mathrm{mg} / \mathrm{kg}$ diluted in olive oil $(0.625 \mathrm{~g} / \mathrm{L}$ diluted in $200 \mu \mathrm{L}$ of olive oil). Control mice were fed olive oil alone (200 $\mu \mathrm{L})$. For the chlordecone-Con A co-exposure model, mice were given a daily gavage of chlordecone or oil for 10 days. They were then intraperitoneally injected with 12 mg/kg Con A (Sigma C2010) or PBS and euthanized $10 \mathrm{~h}$ later (Suppl. Fig 1A). For the chlordecone-MHV3 co-exposure model, mice were maintained in 
individually ventilated cages (Forma Scientific, 1 Marietta, OH) in the BSL3 local animal facility. Mice received daily gavage with $5 \mathrm{mg} / \mathrm{kg}$ chlordecone diluted in olive oil $(0.625 \mathrm{~g} / \mathrm{L}$ diluted in $200 \mu \mathrm{L}$ of olive oil) or oil $(200 \mu \mathrm{L})$ for 10 days. Forin vivo viral inoculation, the pathogenic L2-MHV3 strain were injected by intraperitoneal (i.p.) route at $10^{3} 50 \%$ tissue culture infective dose (TCID50) per animal as described previously (Bleau et al., 2016) or with PBS as control. Mouse blood was collected 48 and $72 \mathrm{~h}$ after infection at the time of euthanasia. In the survival study, mice were weighed daily, morning and evening, and their body temperature measured. In all studies, mice were regularly observed and weighed and their blood was collected at the time of euthanasia. The liver was removed and a total lobe of this organ was fixed for 24 hours in $4 \%$ paraformaldehyde and embedded in paraffin or frozen in liquid nitrogen in the presence of the cryoprotectant isopentane. Serum aspartate aminotransferase (AST) and alanine aminotransferase (ALT) levels were determined according to IFCC primary reference procedures, with an Olympus AU2700 Autoanalyser® (Olympus Optical Optical Co. Ltd., Tokyo, Japan).

\section{Histopathology}

For the assessment of liver injury, $4 \mu$ m-thick sections of paraffin-embedded liver were cut, placed on microscope slides, and stained with hematoxylin and eosin (H\&E). Slides were scanned with a Nanozoomer NDP and images acquired using NDP viewer software. The measurement of necrotic area presented in mouse liver was carried out using the ImageJ software. All necrotic area were selected and measured as a percentage of the total area of the liver section presented on 
the slide. The results showed for the measurement of necrotic area represents the livers of all the mice used in the study.

\section{RNA isolation and RT-qPCR}

We homogenized tissue samples weighing approximately $100 \mathrm{mg}$ and extracted total RNA in Trizol reagent (Invitrogen). The first-strand cDNA was produced with SuperScriptTM I| Reverse Transcriptase (Invitrogen). The cDNA was then amplified, with the GAPDH housekeeping gene as a control. Quantitative PCR was performed with the fluorescent dye SYBR Green and the double strandspecific SYBR® Green system (Applied Biosystems), using an ABI 7900 HT Prism sequence analyzer (Applied Biosystems). Total cDNA (30 ng) was used as a template for amplification, with the specific primer pair used at a final concentration of $300 \mathrm{nM}$. Each measurement was performed in triplicate. We determined 18S mRNA levels as a control, and the level of expression of each gene studied is expressed relative to that of the $18 \mathrm{~S}$ gene. The primers used are presented below:

\begin{tabular}{|l|l|l|}
\hline \multirow{2}{*}{ Gene } & Forward & Reverse \\
\hline $18 S$ & 5'CGCCGCTAGAGGTGAAATTC3' & 5'ATGCACATCAATGTGGAGGA3' \\
\hline N-MHV-3 & 5'TGGAAGGTCTGCACCTGCTA3' & 5'TTTGGCCCACGGGATTG3' \\
\hline IL-8 & 5'AGAGTCCCGCTGACCAAGAG3' & 5'CACTGACAGCGCAGCTCATT3' \\
\hline IL-6 & 5'CTGATGCTGGTGACAACCAC3' & 5'CAGAATTGCCATTGCACAAC3' \\
\hline IFN-Y & 5'AGGTCAACAACCCACAGGTC3' & 5'ATCAGCAGCGACTCCTTTTC3' \\
\hline TNF- $\alpha$ & 5'TAGCTCCCAGAAAAGCAAGC3' & 5'TTTTCTGGAGGGAGATGTGG3' \\
\hline
\end{tabular}

\section{Immune cell isolation and flow cytometry assay}


After euthanasia, mouse livers were perfused through the hepatic portal vein with $2 \mathrm{ml}$ PBS. Immune cells were prepared from liver crushed on a $70 \mu \mathrm{m}$ filter. Liver immune cells were isolated after sedimentation and cell fractionation on a $35 \%$ Percoll layer. For each organ, red blood cells were lysed with the ammoniumchloride-potassium (ACK) buffer. To exclude dead cells from analysis, cell suspensions were labeled for 30 min with LIVE/DEAD fixable yellow stain (Life technologies, L34959). Cells were also pre-incubated with an anti-CD16/32 antibody (dilution 1/100) (BD Pharmingen) to block non-specific binding, before the incubation with the appropriate fluorochrome-conjugated antibodies (BD Pharmingen, eBioscience): anti-CD3-V500 (clone 500A2) (dilution 1/50), antiTCRß-V450 (clone H57-597) (dilution 1/50), anti-CD69-FITC (clone H1.2F3) (dilution 1/100), anti-CD19-APC (clone 1D3) (dilution 1/100), anti-NK1.1-PerCPCy-5.5 (clone PK136) (dilution 1/200), anti-CD4-PE-Cy7 (clone RM4-5) (dilution 1/50), and anti-CD8-APC-Cy7 (clone 53-6.7) (dilution 1/100). The stained cells were analyzed on an Aria II flow cytometer using BD FACSDiva software and the data were processed using CXP software. Dead cells and doublets were excluded based on the forward and side scatter and LIVE/DEAD staining. Immune cell phenotyping was: LT4 : $\mathrm{CD}^{+} / \mathrm{TCRV} \beta^{+} / \mathrm{NK} 1.1^{-} / \mathrm{CD}^{+}$; $\mathrm{LT}^{\mathrm{T}}: \mathrm{CD}^{+} /$ $\mathrm{TCRV}^{+} / \mathrm{NK} 1.1^{-} / \mathrm{CD}^{+} ; \mathrm{NKT}: \mathrm{CD}^{+} / \mathrm{TCRV}^{+} / \mathrm{NK} 1.1^{+} ; \mathrm{NK}: \mathrm{CD} 3^{-} / \mathrm{NK} 1.1^{+} ; \mathrm{LB}: \mathrm{CD} 19$ +/CD3; macrophages: CD11b+GR1 ${ }^{\text {int; }}$; and neutrophils: CD11b+/GR $1^{\text {high }}$. CD69 was used to study lymphoid cell activation.

\section{Statistical analysis}

Kruskal-Wallis one-way analysis of variance (ANOVA) was performed and mean differences between experimental groups were assessed using the 
nonparametric Mann-Whitney U-test with GraphPad Prism5 software. For all statistical analyses, ${ }^{*}$ denotes $p<0.05,{ }^{* *} p<0.01$ and ${ }^{* *} p<0.001$.

\section{Results}

\section{The effects of chlordecone on murine auto-immune hepatitis}

We investigated the effect of chlordecone on acute auto-immune hepatitis in a mouse model of co-exposure to chlordecone and Con A. Chlordecone gavage induced hepatomegaly in the mice (Fig. 1A). Con A administration alone increased AST and ALT levels in the blood and the level of ALT was significantly increased further when the mice were co-exposed to chlordecone (Fig. 1B and 1C). Histological studies of the mouse livers have shown no necrotic areas when mice were treated with chlordecone alone or oil alone (data not shown). In contrast, mouse livers showed more necrotic areas in the liver of mice coexposed to chlordecone and Con A than those treated with oil and Con A (Fig. 1D). The percentage of necrotic area per liver presented a significantly increase between the livers of mice treated with oil + Con A and those treated with chlordecone + Con A (Fig. 1E). These results show that chlordecone amplifies Con A-induced hepatitis in mice.

We analyzed the liver immune cell phenotypes in mice treated, or not, with chlordecone to better understand the mechanism which leads to increased hepatic damage. As expected, chlordecone induced hepatomegaly (Fig. 2A) without affecting the total number of immune cells in the liver (Fig. 2B). However, chlordecone significantly increased the number of NKT cells in the liver (Fig. 2C), with no effect on other immune-cell populations, such as T4 and T8 lymphocytes, NK cells, B lymphocytes, resident macrophages, and neutrophils (Fig. 2D). 
Assessment of the T-cell activation marker, CD69, mostly expressed on NKT cells, showed NKT cells to be significantly more highly activated in the livers of mice treated with chlordecone than in control mice treated with oil (Fig. 2E). These results show that NKT cells, the main effector cells in Con A-induced hepatitis, were already numerous and activated by chlordecone, before treatment with Con A.

\section{The effect of chlordecone on the survival of mice infected with MHV3}

The impact of chlordecone on viral hepatitis was studied in a mouse model of coexposure to chlordecone and MHV3. Treatment with chlordecone induced hepatomegaly (Fig. 3A). As expected, liver damage observed by histological analysis or indirectly by measuring hepatic transaminases levels in the serum of mice showed important damages in livers of mice infected with MHV-3 alone (Fig. 3B, 3C and 3D) compared to liver from uninfected mice (data not shown). Nevertheless, there was no significant difference in liver damage, between the two treated groups (oil + MHV3 or chlordecone + MHV3) (Fig. 3B, 3C and 3D), suggesting that chlordecone does not potentiate MHV3-induced viral hepatitis.

Mice infected by MHV3 virus alone die after a few days. We thus compared the survival of mice treated with Oil + MHV3 to those treated with chlordecone + MHV3. The two groups showed no difference in the weight loss and decrease in body temperature caused by MHV3 (Fig. 4A and 4B). However, mice pretreated with chlordecone died significantly earlier than those that received oil (Fig. 4C). We quantified the level of MHV3 virus in the liver and brain by measuring the expression of the MHV3 nucleocapsid gene by quantitative real-time PCR 72 hours after infection. There was no significant difference in MHV3 expression due 
to chlordecone pretreatment in the liver (Fig. 5A), whereas the expression of the MHV3 nucleocapsid gene was significantly higher in the brains of mice pretreated with chlordecone (Fig. 5B). We determined whether the entry of the virus into the brain can cause an inflammatory response by the host by measuring the expression of the transcripts of IL-8, IL-6, IFN $\gamma$, and TNF $\alpha 72$ hours post-infection. Chlordecone alone did not change the expression of the inflammatory cytokines in the brain, whereas MHV3 infection of mice treated with chlordecone increased the levels of IL-6, IL-8, and TNF $\alpha$ (Fig. 6).

\section{Discussion}

Published studies have shown the ability of chlordecone to potentiate the hepatotoxicity of various toxic agents when they are administered together. Hepatotoxic agents used in these studies were exclusively chemicals or drugs, such as acetaminophen, chloroform, and carbon tetrachloride (Bell and Mehendale, 1985; Cianflone et al., 1980; Fouse and Hodgson, 1987). No study has been conducted to measure the impact of chlordecone on other hepatitis etiologies, such as autoimmune or viral hepatitis. Here, we investigated the effect of chlordecone on two types of acute hepatitis in mice. The first was a murine model of exposure to chlordecone during autoimmune hepatitis induced by Con A. Previous studies have shown that chlordecone accelerates systemic autoimmune diseases, such as lupus erythematosus (Sobel et al., 2006). Indeed, chronic treatment with relatively low doses of chlordecone accelerate the development of systemic lupus erythematosus in ovariectomized or control female (NZBxNZW) F(1) mice, but not in BALB/c mice, demonstrating the ability of chronic chlordecone to influence systemic lupus erythematosus depending on 
the genetic background (Sobel et al., 2006). However, the mode of action of chlordecone in immunity remains unknown. In the systemic lupus erythematosus, Sobel et al. (Sobel et al., 2005) hypothesized that chlordecone's acceleration of autoimmunity may be related to its estrogenic properties and ability of chlordecone to bind the estrogen receptor. However several studies show that the mode of action of chlordecone is unrelated to their estrogenicity (Wang et al., 2008) (Sobel et al., 2006) (Wang et al., 2007). Another work reports that chlordecone alone, independently of these estrogenic properties, increased secretion of IFN-gamma and GM-CSF, but not IL-10 secretion and chlordecone exerts own effects on splenic T-cells (Wang et al., 2008). Thus, chlordecone exerts own effects on immune cells but its mechanism of action unknown. Up to date, no study has been conducted on auto-immune liver diseases. Here, we show that chlordecone potentiates the auto-immune hepatitis induced by Con A, with a higher level of liver transaminases in serum and greater hepatic necrosis in mice co-exposed to chlordecone and Con A than those treated with Con A alone. Phenotypic analysis of resident immune cells in the liver showed that among the immune cells analyzed, only the number of hepatic NKT cells increased after chlordecone exposure and was two times higher than in those of unexposed mice. Moreover, chlordecone can activate the hepatic NKT cell population, as demonstrated by increased levels of CD69. It is known that chlordecone exerts effects on splenic T-cells (Wang et al., 2008). Here, we find out that NKT cells is a new population impacted directly or indirectly by chlordecone. This may explain the potentiating effect of chlordecone on Con A-induced hepatitis, which depends on hepatic NKT-cell stimulation (Takeda et al., 2000; Wang et al., 2012). 
The second experimental model was a murine model of exposure to chlordecone during an infection with MHV3. We show that the hepatitis induced by this virus was not amplified by chlordecone in this model, as shown by the hepatic transaminase levels in the serum and histological analysis of livers. In contrast, mice co-exposed to chlordecone and MHV3 died earlier than those infected only by the virus. Moreover, the amount of virus in the brains of mice was much higher when they were co-exposed to chlordecone, as well as that of several inflammatory cytokines. Thus, the input or replication of MHV3 virus in the brains of mice was promoted by chlordecone. We previously demonstrated that invasion of the brain in MHV3-infected mice correlates with enhanced blood-brain barrier (BBB) permeability associated with decreased expression of zona occludens protein 1 (ZO-1), VE-cadherin, and occludin, but not claudin-5, in the brain or cultured brain microvascular endothelial cells (Bleau et al., 2015). Chlordecone, which is known to cause neurological disorders, can also generate alterations in mouse brain by altering the content and subcellular distribution of calcium (Desaiah, 1982);(Hoskins and Ho, 1982);(Huang et al., 1981; Tilson and Mactutus, 1982), but the mechanism involved is not yet clearly elucidated. It is possible that chlordecone alters or increases alterations of the $\mathrm{BBB}$, thus favoring viral entry, resulting in increased levels of inflammatory cytokines, both leading to alterations in the distribution of $\mathrm{Ca}^{++}$. However, no work reports the effects of chlordecone on the blood-brain barrier. Thus in this study, greater neurological damage in mice co-exposed to chlordecone and MHV3 virus than those exposed to the virus alone may explain their early death.

In conclusion, these two approaches open new avenues for research on the mechanisms of co-exposure to chlordecone and hepatotoxic agents and new 
epidemiological research pathways for patients with acute or chronic liver diseases. Indeed, the evolution of fulminant hepatitis in the populations living in areas contaminated by chlordecone should be evaluated to determine whether blood levels of chlordecone affect the outcome of fulminant hepatitis caused by autoimmune hepatitis or viral hepatitis.

\section{Figure legends}

Figure 1. Effect of chlordecone on Con A-induced acute hepatitis. Mice received oral gavage with olive oil or $5 \mathrm{mg} / \mathrm{Kg}$ chlordecone. After 10 days, they were injected with $12 \mathrm{mg} / \mathrm{Kg}$ Con A and euthanized 8-h post-injection. A) Liver-to-body weight ratio, showing the occurrence of hepatomegaly in the treated mice. B) Serum levels of AST (IU/L) at the time of euthanasia. C) Serum levels of ALT (IU/L) at the time of euthanasia. D) Liver sections stained with hematoxylin and eosin, showing necrotic areas. The data shown are the means \pm SD for 10 animals per group. The significance of the difference between groups was evaluated by the Mann-Whitney test. ${ }^{*} \mathrm{P}<0.05,{ }^{* * *} \mathrm{P}<0.001$

Figure 2. Effect of chlordecone on hepatic immune cells. Mice received oral gavage with olive oil or $5 \mathrm{mg} / \mathrm{Kg}$ chlordécone for 10 days. A) Liver-to-body weight ratio, showing the occurrence of hepatomegaly in the treated mice. B) Number of hepatic immune cells. C) Immune cell characterization strategy for flow cytometry. D) Percentage of hepatic immune cell populations. E) Percentage of NKT cells in the liver. F) Percentage of CD69 ${ }^{+}$NKT cells in the liver. The data shown are the means $\pm S D$ for four animals per group. The significance of the difference 
between groups was evaluated by the Mann-Whitney test. ${ }^{*} \mathrm{P}<0.05$, ${ }^{* *} \mathrm{P}<0.01$, ${ }^{* * *} \mathrm{P}<0.001$

Figure 3. Effect of chlordecone on MHV3 virus-induced acute hepatitis. Mice received oral gavage with olive oil or $5 \mathrm{mg} / \mathrm{Kg}$ chlordécone for 10 days. They were then infected, or not, with MHV3 virus and euthanized $72 \mathrm{~h}$ post-infection. A) Liver-to-body weight ratio, showing the occurrence of hepatomegaly in the treated mice. B) Serum levels of AST (IU/L) at the time of euthanasia. C) Serum levels of ALT (IU/L) at the time of euthanasia. D) Liver sections stained with hematoxylin and eosin showing necrotic areas (black arrow). The data shown are the means \pm SD for 12 animals per group. The significance of the difference between groups was evaluated by the Mann-Whitney test. ${ }^{* \star} \mathrm{P}<0.01$

Figure 4. Effect of chlordecone on survival after MHV3 infection. A) Percentage weight loss. B) Percentage loss of body temperature. C) Percentage survival after MHV3 infection. The data shown are the means \pm SD for 12 animals per group. The significance of the difference between groups was evaluated by the MannWhitney test $P<0.05$

Figure 5. Expression of the MHV3 virus nucleocapsid gene. A) Expression in the liver. B) Expression in the brain. Liver and brain total RNA was extracted from mice treated with oil, chlordecone, oil + MHV3, or chlordecone + MHV3. After RTPCR analysis, mRNA levels were expressed as the ratios relative to $18 \mathrm{~S}$ levels. The data shown are the means \pm SD for seven animals in each group. The 
significance of the difference between groups was evaluated by the MannWhitney test. ${ }^{*} \mathrm{P}<0.05$

Figure 6. Reverse transcription-PCR analysis of inflammatory cytokines in mouse brain. (A) IL-8. (B) IL-6. (C) IFN- . (D) TNF- $\alpha$. Brain total RNA was extracted from mice treated with oil, chlordecone, oil $+\mathrm{MHV} 3$, or chlordecone $+\mathrm{MHV} 3$ as described in the materials and methods. After RT-PCR analysis, mRNA levels were expressed as the ratios relative to $18 \mathrm{~S}$ levels. The data shown are the means \pm SD for seven animals in each group. The significance of the difference between groups was evaluated by the Mann-Whitney test. ${ }^{*} \mathrm{P}<0.05,{ }^{* *} \mathrm{P}<0.01$

\section{ACKNOWLEDGMENTS}

This work was supported by INSERM, the Universite de Rennes 1, and the ANR (Agence Nationale de la Recherche)- CESA, Hepatochlor project. We would like to thank the dedicated platforms for immunohistochemistry and animal house facilities (i.e. H2P2 (Pascale Bellaud and Roselyne Viel), Arche (Laurence Bernard) of SFR BIOSIT, University of Rennes 1, France.

\section{REFERENCES}

Bell, A.N., Mehendale, H.M., 1985. The effect of dietary exposure to a mirex plus chlordecone combination on CCl4 hepatotoxicity. Fundam Appl Toxicol 5, 679-687.

Bleau, C., Burnette, M., Filliol, A., Piquet-Pellorce, C., Samson, M., Lamontagne, L., 2016. Toll-like receptor-2 exacerbates murine acute viral hepatitis. Immunology 149 , 204-224. 
Bleau, C., Filliol, A., Samson, M., Lamontagne, L., 2015. Brain Invasion by Mouse Hepatitis Virus Depends on Impairment of Tight Junctions and Beta Interferon Production in Brain Microvascular Endothelial Cells. J Virol 89, 9896-9908.

Cannon SB, V.J.J., Jackson RS, Burse VW, Hayes C, StraubWE, Landrigan PJ, L.J., 1978. Epidemic kepone poisoning in chemical workers. Am J Epidemiol, 529-537.

Cianflone, D.J., Hewitt, W.R., Villeneuve, D.C., Plaa, G.L., 1980. Role of biotransformation in the alterations of chloroform hepatotoxicity produced by Kepone and mirex. Toxicol Appl Pharmacol 53, 140-149.

Desaiah, D., 1982. Biochemical mechanisms of chlordecone neurotoxicity: a review. Neurotoxicology 3, 103-110.

Egle, J.L., Fernandez, J.B., Guzelian, P.S., Borzelleca, J.F., 1978. Distribution and excretion of chlordecone (Kepone) in the rat. Drug Metab Dispos 6, 91-95.

Fouse, B.L., Hodgson, E., 1987. Effect of chlordecone and mirex on the acute hepatotoxicity of acetaminophen in mice. Gen Pharmacol 18, 623-630.

Guzelian, P.S., 1982. Comparative toxicology of chlordecone (Kepone) in humans and experimental animals. Annu Rev Pharmacol Toxicol 22, 89-113.

Hoskins, B., Ho, I.K., 1982. Chlordecone-induced alterations in content and subcellular distribution of calcium in mouse brain. J Toxicol Environ Health 9, 535-544.

Huang, T.P., Ho, I.K., Mehendale, H.M., 1981. Assessment of neurotoxicity induced by oral administration of chlordecone (Kepone) in the mouse. Neurotoxicology 2, 113-124.

Iijima, M., Cote, M.G., Plaa, G.L., 1983. A semiquantitative morphologic assessment of chlordecone-potentiated chloroform hepatotoxicity. Toxicol Lett 17, 307-314.

Klingensmith, J.S., Lockard, V., Mehendale, H.M., 1983. Acute hepatotoxicity and lethality of CCl4 in chlordecone-pretreated rats. Exp Mol Pathol 39, 1-10.

Klingensmith, J.S., Mehendale, H.M., 1982. Potentiation of CCl4 lethality by chlordecone. Toxicol Lett 11, 149-154.

Lagarrigue, M., Lavigne, R., Tabet, E., Genet, V., Thome, J.P., Rondel, K., Guevel, B., Multigner, L., Samson, M., Pineau, C., 2014. Localization and in situ absolute quantification of chlordecone in the mouse liver by MALDI imaging. Anal Chem 86, 5775-5783.

Martin, J.P., Chen, W., Koehren, F., Pereira, C.A., 1994. The virulence of mouse hepatitis virus 3, as evidenced by permissivity of cultured hepatic cells toward escape mutants. Res Virol 145, 297-302.

Ponde, R.A.A., 2017. The serological markers of acute infection with hepatitis A, B, C, D, E and G viruses revisited. Arch Virol 162, 3587-3602. 
Skalsky, H.L., Fariss, M.W., Blanke, R.V., Guzelian, P.S., 1979. The role of plasma proteins in the transport and distribution of chlordecone (Kepone) and other polyhalogenated hydrocarbons. Ann N Y Acad Sci 320, 231-237.

Sobel, E.S., Gianini, J., Butfiloski, E.J., Croker, B.P., Schiffenbauer, J., Roberts, S.M., 2005. Acceleration of autoimmunity by organochlorine pesticides in (NZB x NZW)F1 mice. Environ Health Perspect 113, 323-328.

Sobel, E.S., Wang, F., Butfiloski, E., Croker, B., Roberts, S.M., 2006. Comparison of chlordecone effects on autoimmunity in (NZBxNZW) $\mathrm{F}(1)$ and BALB/c mice. Toxicology 218, 81-89.

Soine, P.J., Blanke, R.V., Guzelian, P.S., Schwartz, C.C., 1982. Preferential binding of chlordecone to the protein and high density lipoprotein fractions of plasma from humans and other species. J Toxicol Environ Health 9, 107-118.

Tabet, E., Genet, V., Tiaho, F., Lucas-Clerc, C., Gelu-Simeon, M., Piquet-Pellorce, C., Samson, M., 2016. Chlordecone potentiates hepatic fibrosis in chronic liver injury induced by carbon tetrachloride in mice. Toxicol Lett.

Takeda, K., Hayakawa, Y., Van Kaer, L., Matsuda, H., Yagita, H., Okumura, K., 2000. Critical contribution of liver natural killer T cells to a murine model of hepatitis. Proc Natl Acad Sci U S A 97, 5498-5503.

Taylor, J.R., Selhorst, J.B., Houff, S.A., Martinez, A.J., 1978. Chlordecone intoxication in man. I. Clinical observations. Neurology 28, 626-630.

Tiegs, G., Hentschel, J., Wendel, A., 1992. A T cell-dependent experimental liver injury in mice inducible by concanavalin A. J Clin Invest 90, 196-203.

Tilson, H.A., Mactutus, C.F., 1982. Chlordecone neurotoxicity: a brief overview. Neurotoxicology 3, 1-8.

Wang, F., Roberts, S.M., Butfiloski, E.J., Sobel, E.S., 2007. Diminished prolactin from chlordecone treatment in ovariectomized (NZBxNZW)F(1) mice. Int Immunopharmacol 7, 1808-1812.

Wang, F., Sobel, E.S., Butfiloski, E.J., Roberts, S.M., 2008. Comparison of chlordecone and estradiol effects on splenic T-cells in (NZBxNZW)F(1) mice. Toxicol Lett 183, 1-9.

Wang, H.X., Liu, M., Weng, S.Y., Li, J.J., Xie, C., He, H.L., Guan, W., Yuan, Y.S., Gao, J., 2012. Immune mechanisms of Concanavalin A model of autoimmune hepatitis. World J Gastroenterol 18, 119-125. 
ס

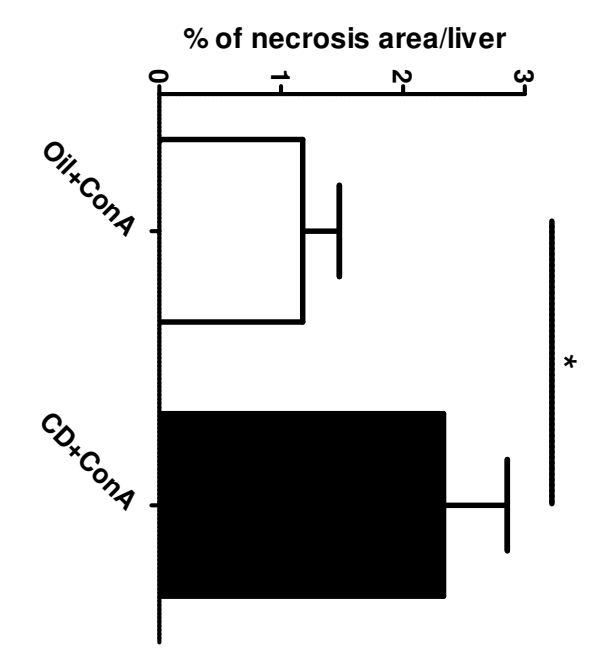

1
0
$\frac{1}{+}$
$\frac{1}{3}$
$\frac{1}{7}$
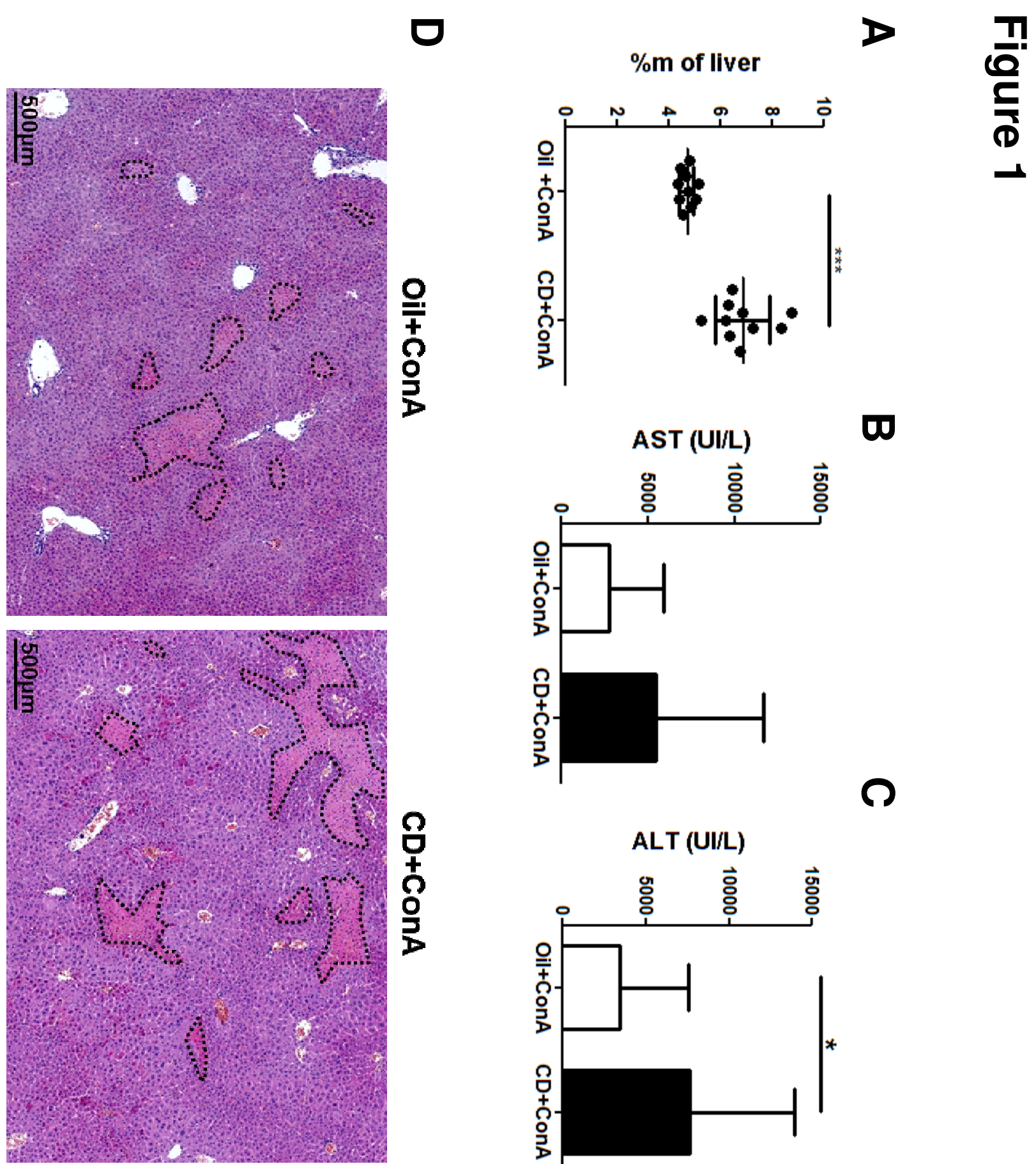

$\frac{7}{\frac{1}{0}}$

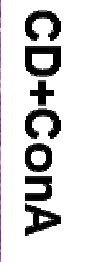
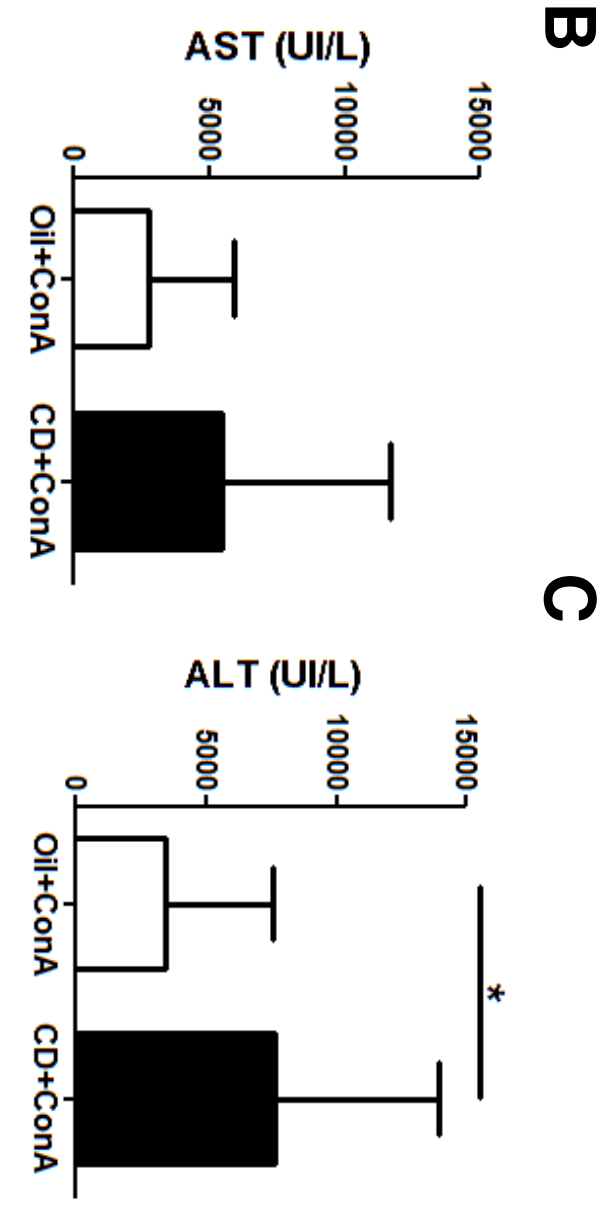
Figure 2

A

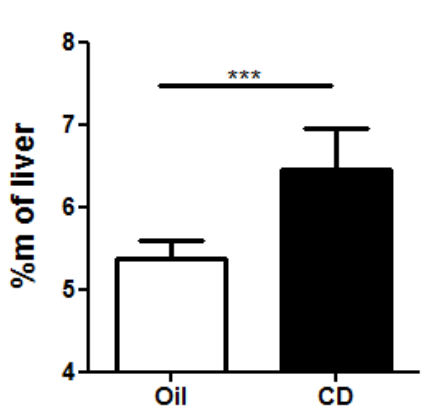

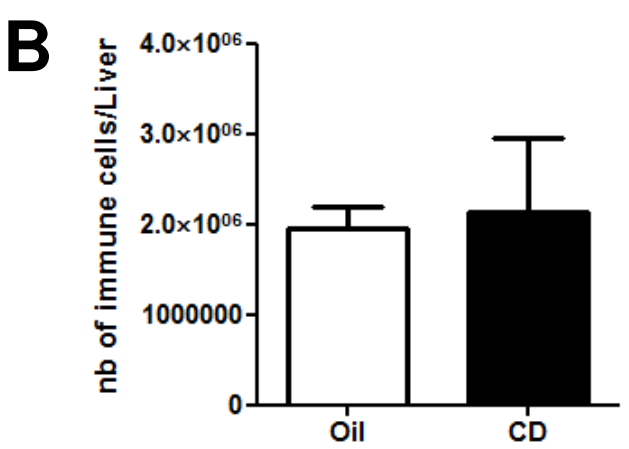

C

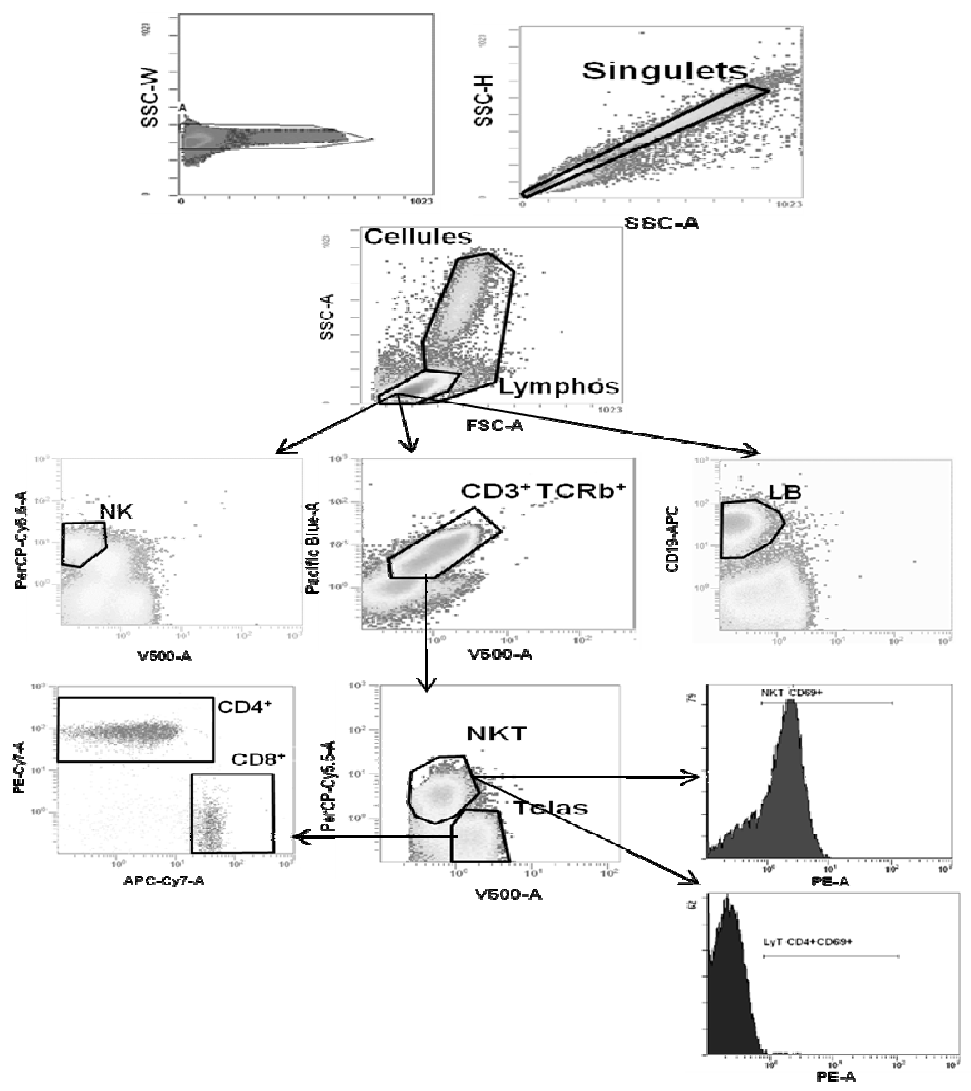

D

\begin{tabular}{|c|c|c|}
\hline \% immune cells/Liver & Oil & CD \\
\hline LT4 & $14,73 \pm 1,21$ & $15,02 \pm 3,41$ \\
\hline LT8 & $10,10 \pm 2,22$ & $9,47 \pm 1,52$ \\
\hline NKT & $\mathbf{9 , 6 2} \pm 3,75$ & $\mathbf{1 5 , 9 8} \pm 4,66$ \\
\hline NK & $8,87 \pm 2,77$ & $8,41 \pm 1,25$ \\
\hline LB & $41,39 \pm 7,84$ & $35,75 \pm 5,19$ \\
\hline Macrophages & $11,25 \pm 2,21$ & $11,85 \pm 4,03$ \\
\hline Neutrophils & $4,02 \pm 1,05$ & $3,5 \pm 2,17$ \\
\hline
\end{tabular}

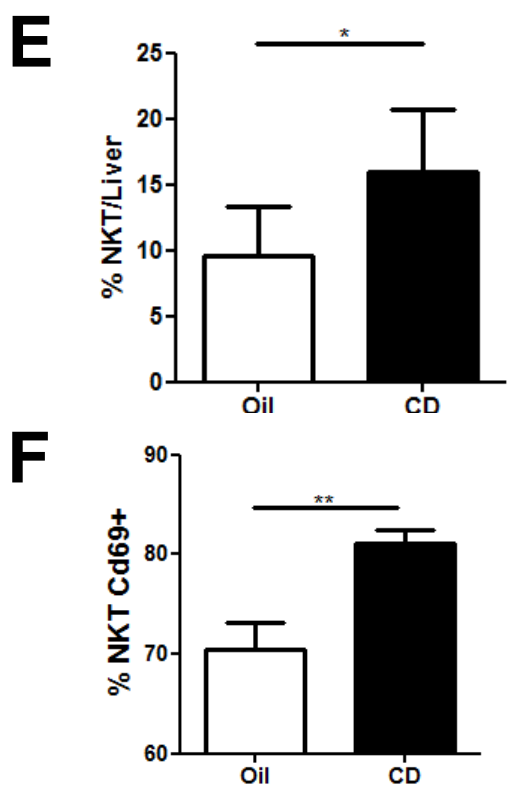


Figure 3

A

B

-

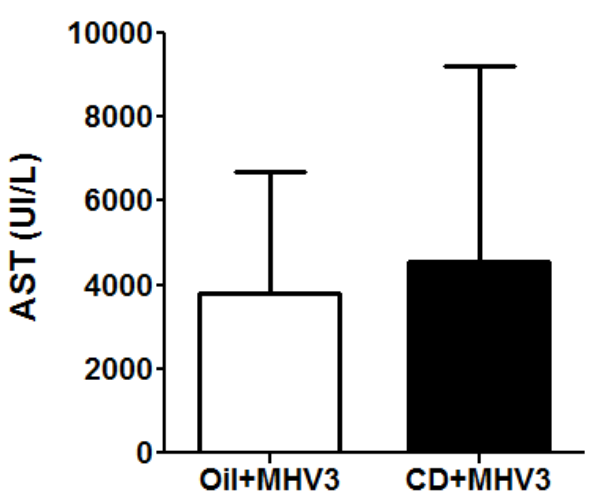

C

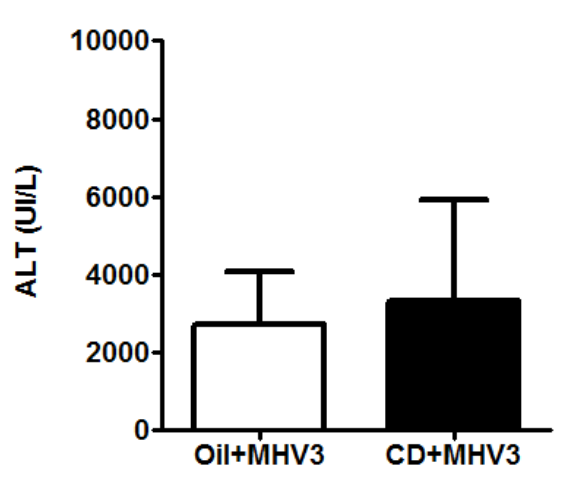

D Oil+MHV3

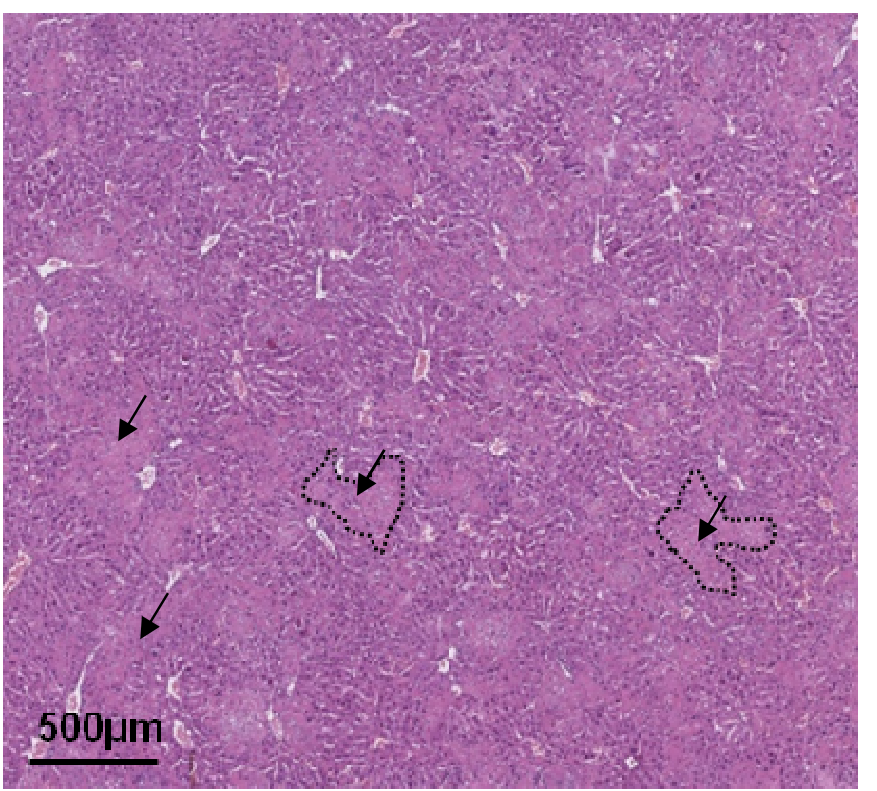

CD+MHV3

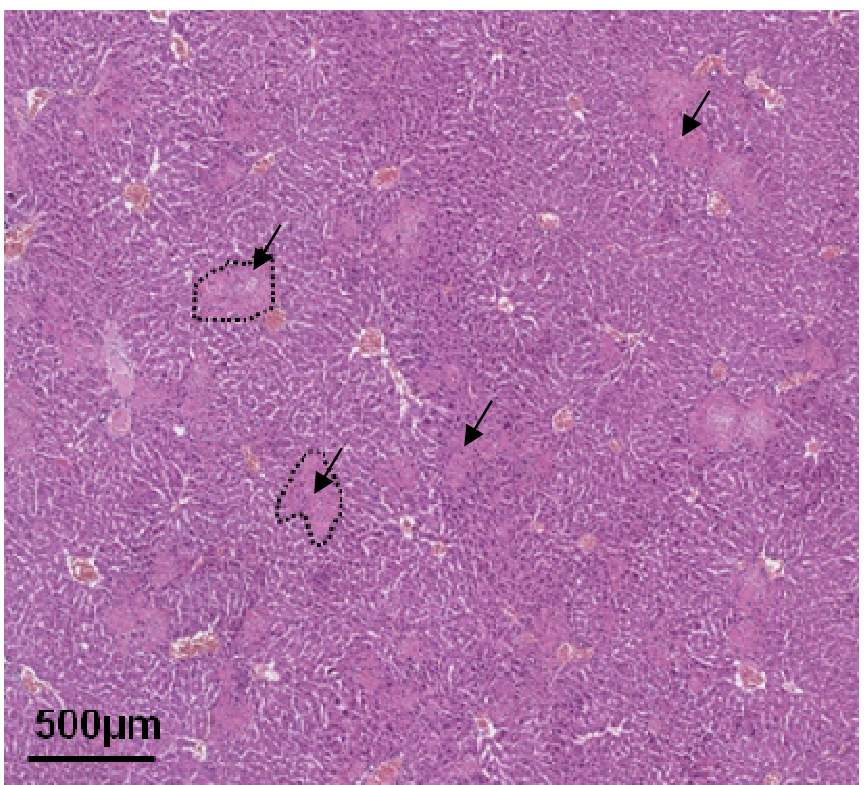


Figure 4
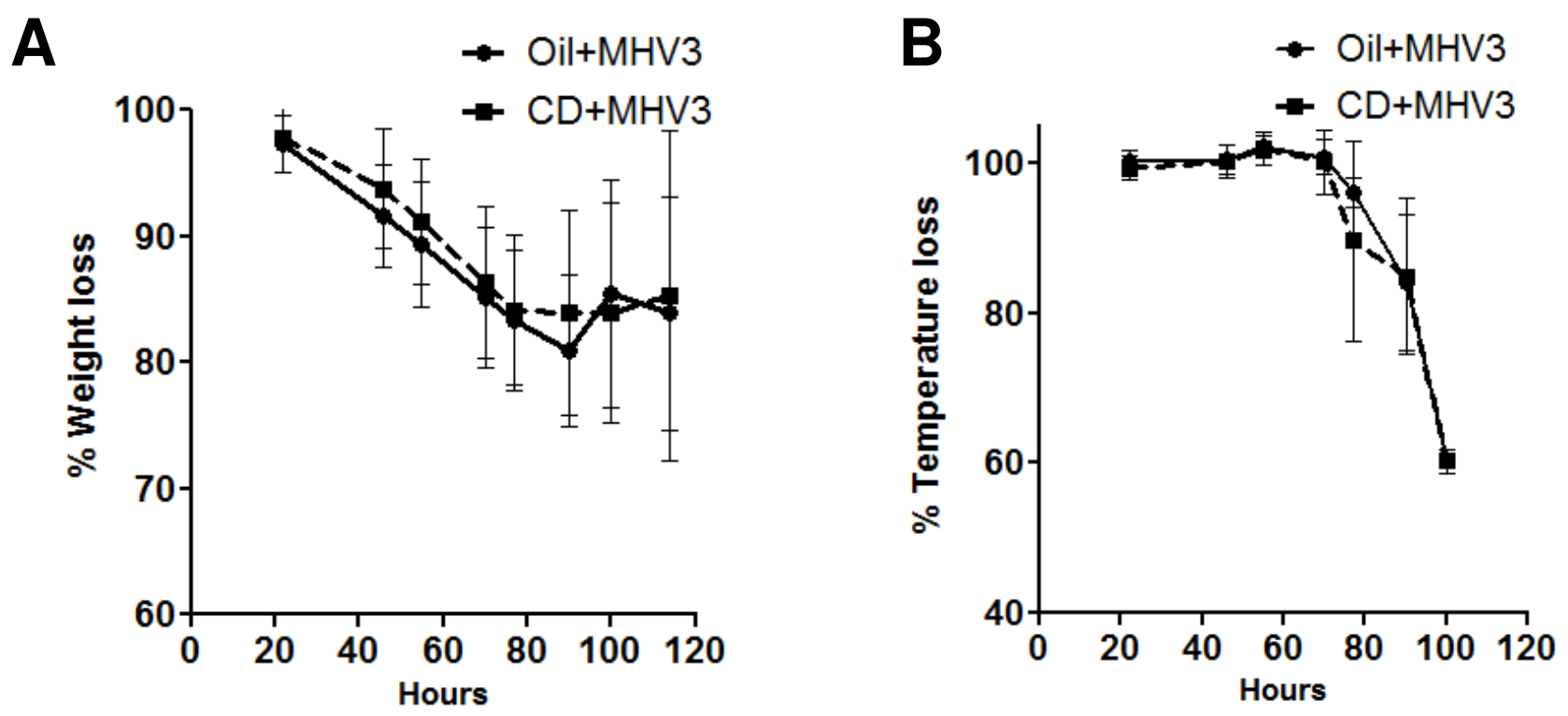

C

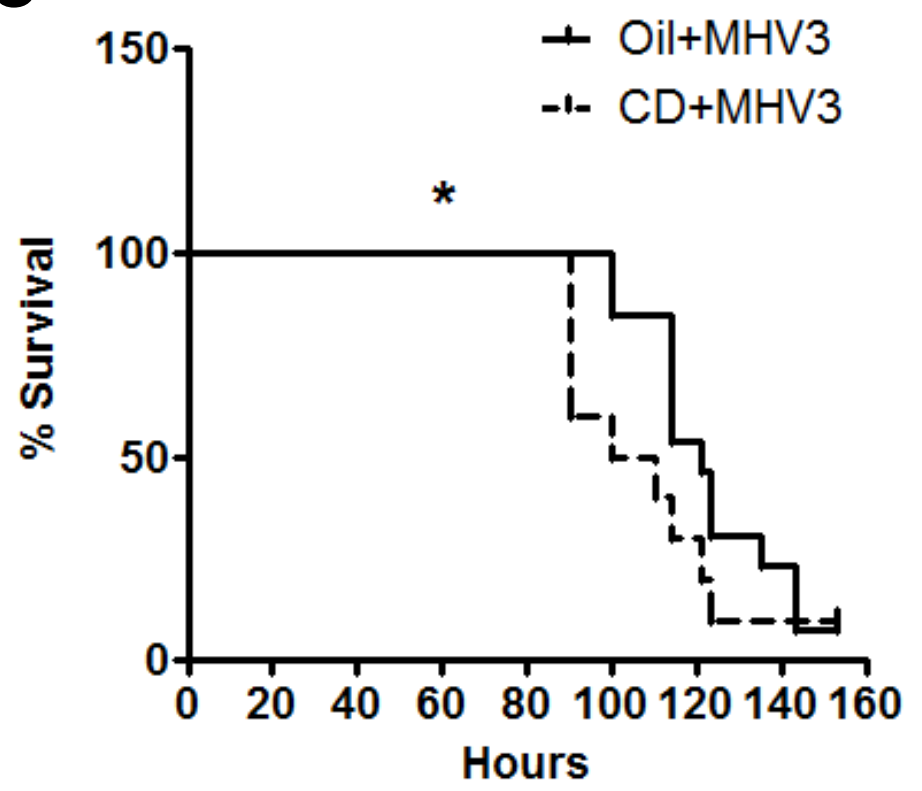


Figure 5
A
Liver
B
Brain
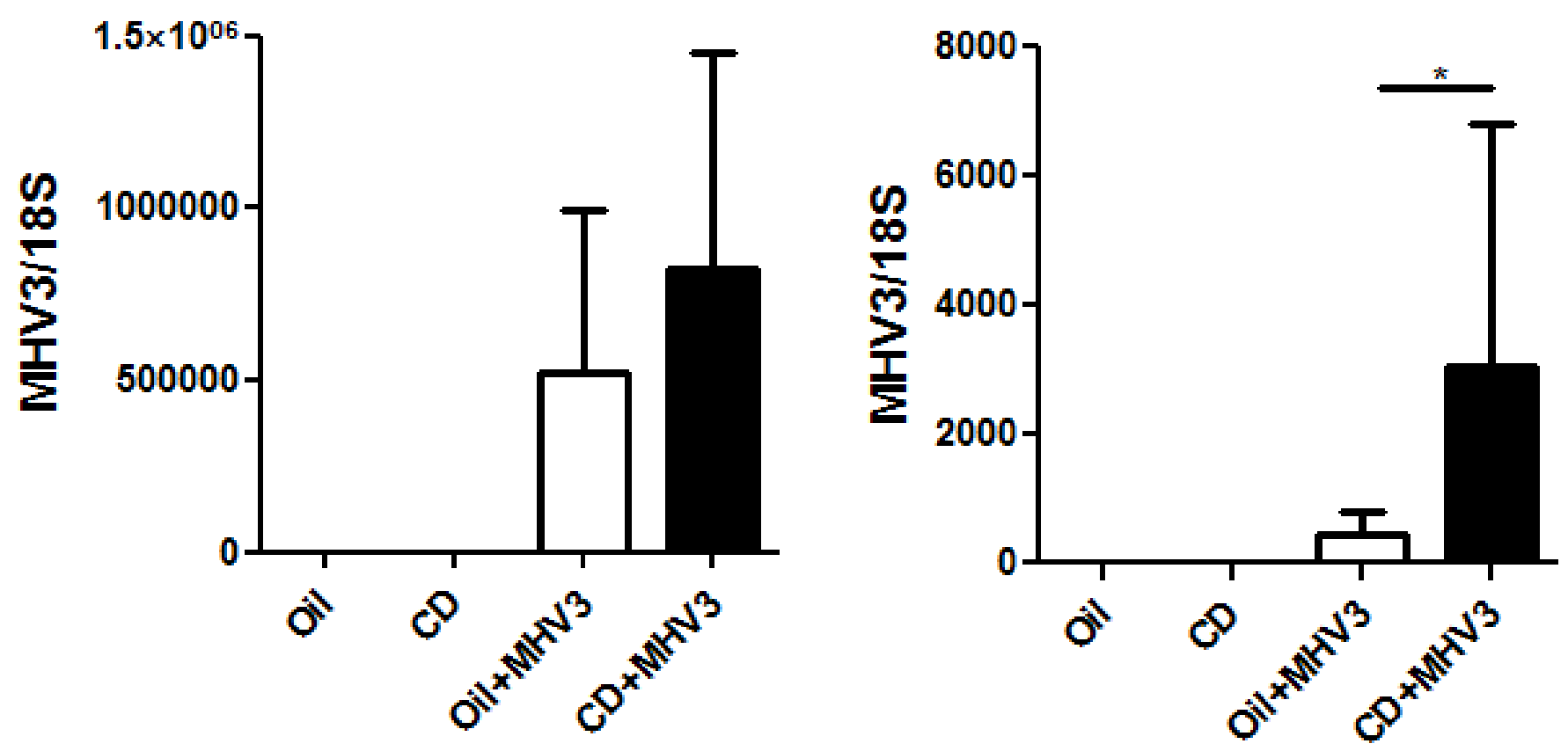
Figure 6
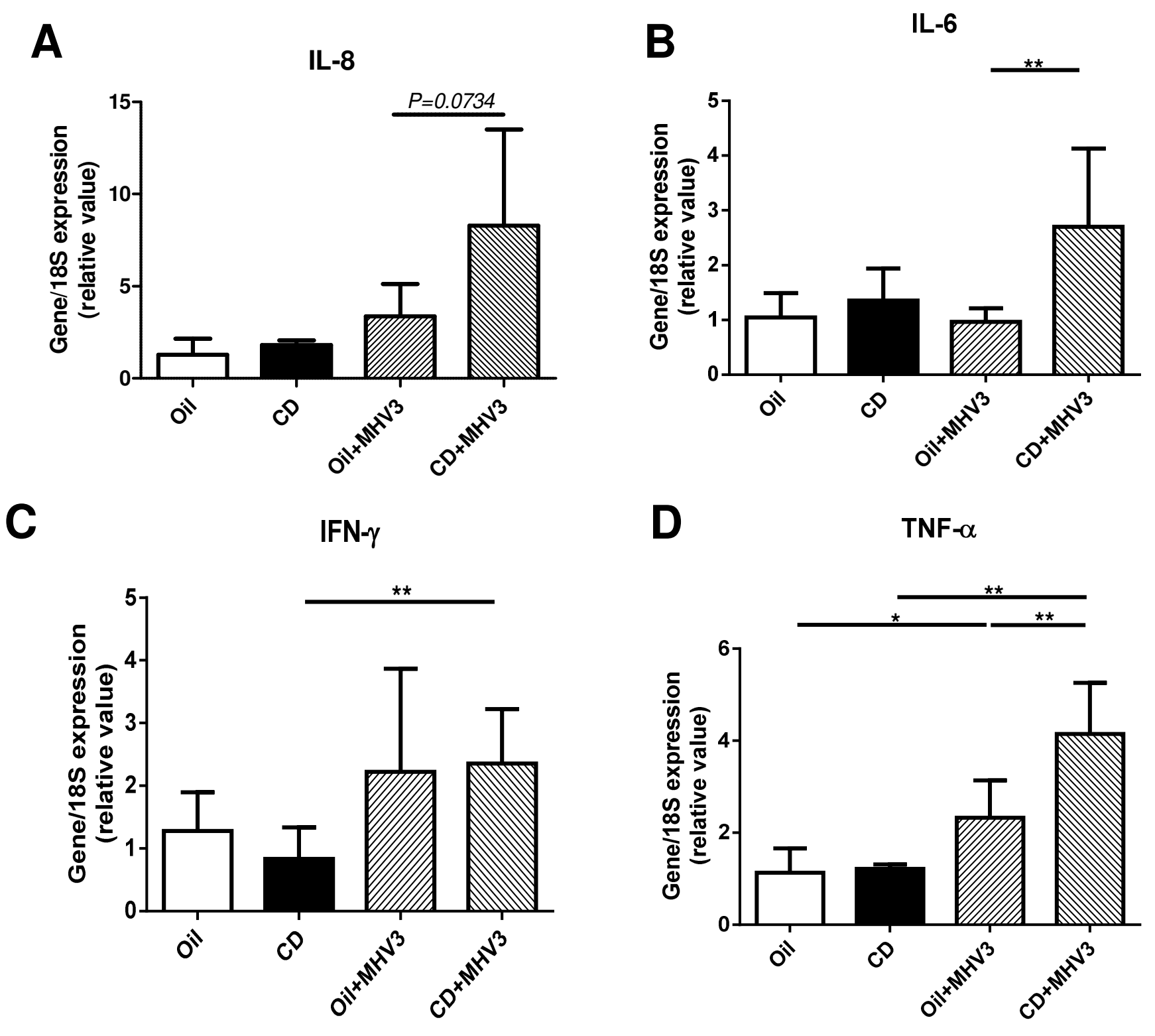
